Case report

\title{
Celiac disease: uncommon, oligosymptomatic course of illness, with profound hypoalbuminemia in an adult patient
}

\author{
Łukasz Lis*, Andrzej Konieczny, Patryk Jerzak, Paweł Podgórski, Krzysztof Benc, \\ Zbigniew Hruby
}

Department of Nephrology, Renal Transplantation and Internal Medicine, Research and Development Center, Provincial Specialist Hospital in Wrocław, Poland

\begin{abstract}
Celiac disease $(C D)$ is an immune-mediated disease, caused by gluten, occurring in people with genetic predisposition. The course of the disease can vary and includes both intestinal and extra-intestinal manifestations. Many patients are undiagnosed for many years and some of them, in particular with nonspecific symptoms or asymptomatic, might never be diagnosed. We present a rare case of a patient, who's first and practically the only symptom of the disease was a pathological fracture of the ribs. In addition, despite the lack of clinical symptoms of malabsorption syndrome, malnutrition and proteinuria, we observed profound hypoalbuminemia and hypoproteinemia. This case suggests that CD diagnostic should be undertaken in evaluation of every patient with osteoporotic fractures and hypoalbuminemia.
\end{abstract}

Keywords: celiac disease; hypoalbuminemia; autoimmune diseases

\section{Introduction}

Celiac disease (CD) is an immunemediated disease, caused by gluten, occurring in people with genetic predisposition (with HLA-DQ2 or DQ8 genotypes) [1]. After exposure to gluten, specific antibodies as TG2 (anti-transglutaminase antibodies), EMA (antiendomysial antibodies) and DGP (deamidated gliadin peptide antibodies) are synthesized, causing an autoimmune inflammatory reaction, leading to an atrophy of villi of the small intestinal mucosa [2]. Its incidence, both in the US and Europe, is estimated at 11.8-17.4 per 100000 person years [3].

Received: April 2019; Accepted after review: June 2019; Published: June 2019.

${ }^{*}$ Corresponding author: Łukasz Lis, Research and Development Center, Provincial Specialist Hospital in Wrocław, H. M. Kamieńskiego 73A, 51-124 Wrocław, Poland.

Email: lislukasz@ymail.com
The course of the disease can vary and can include both intestinal and extra-intestinal manifestations (EIM). The classic (known also as intestinal) symptoms include: malabsorption syndrome consisting of diarrhea, abdominal pain, vomiting and as a result - malnutrition and growth disorders. Non-classical (extraintestinal) symptoms include iron deficiency anemia, tetany, dermatitis herpetiformis, epilepsy, migraine, depression, ataxia, peripheral polyneuropathy and muscular weakness [4].

Untreated, unrecognized and refractory celiac disease, with symptoms persisting despite adherence to a diet eliminating gluten, leads to serious complications like: neoplasms from the digestive tract (throat cancer, esophagus cancer, small intestine cancer or small intestinal lymphoma), from the hematopoietic system (non-Hodgkin's lymphoma, hyposplenism), from the genitourinary system (infertility, habitual miscarriage, preterm delivery, premature 
menopause) and from the bones (osteoporosis and osteomalacia) $[5,6]$.

The celiac disease diagnostic criteria include: positive serology (autoantibodies against TG2, EMA in the $\operatorname{IgA}$ and $\lg$ class and against deamidated gliadin peptides) and typical histopathological findings (atrophy of the intestinal villi, accompanied by an increase in number of intraepithelial lymphocytes and crypt hypertrophy) [7].

In a differential diagnosis it should be considered among others: chronic giardiasis, protein malnutrition, anorexia nervosa, food hypersensitivity, viral infections (including HIV) and bacterial (including tuberculosis), bacterial growth syndrome, Whipple's disease, immunodeficiency, Crohn's disease, ulcerative colitis, colorectal lymphoma [8].

The average time to diagnosis, after onset of symptoms for adults with $C D$ ranges from 4 to 12 years [9].

Nowadays, strict compliance with gluten free diet (GFD) is the only therapeutic regimen; however, it is not uniformly successful in all patients [10].

We report an uncommon case of celiac disease, diagnosed in an adult oligosymptomatic male, during investigation of profound hypoproteinemia and hypoalbuminemia.

\section{Case report}

We present a case of a 38-years old Caucasian man, a worker, admitted to the department of internal diseases, due to profound deficiency of both total blood protein and albumin, which were incidentally detected by analysis of outpatient laboratory tests, during the diagnosis of ribs' pain. In the interview, the patient reported a degenerative disease of the lumbar spine (L5-S1 discopathy confirmed by the outpatient MRI), nicotinism and acute pancreatitis on the toxic background 7 years ago.

He also complained of the ribs' pain, lasting for about 7 months, varying in severity and recurrent swelling of the left knee. At the time of admission, the patient did not present lower limbs edema nor reported any other complaints.

The man denied diarrhea, abdominal pain, fever, vomiting, weight loss, cough, hemoptysis, skin rash, frequent infections nor urinary disorders in the past few years.

The patient consumed normal meals, including meat products, defecated once a day without pathological admixtures and denied alcohol consumption for last 7 years.

During the physical examination at admission, the patient was in good general condition, except for ribs' tenderness on both sides, no other abnormalities were found. His Body Mass Index (BMI) was 20.

Initial laboratory tests showed in serum: low albumin concentration $1.7 \mathrm{~g} / \mathrm{dL}$, hypoproteinemia $2.8 \mathrm{~g} / \mathrm{dL}$, hypocalcemia (Ca total $1.7 \mathrm{mmol} / \mathrm{L}$, Ca corrected $2.16 \mathrm{mmol} / \mathrm{L}$ ), slightly elevated alkaline phosphatase (194 IU/L) and parathyroid hormone level (189 $\mathrm{pg} / \mathrm{mL})$, vitamin $D$ deficiency $(13.3 \mathrm{ng} / \mathrm{mL}$ ), lymphopenia (0.7/uL) with normal other morphological values $(\mathrm{Hb} 16.6 \mathrm{~g} / \mathrm{dL}, W B C$ $7.73 \times 10^{9} / \mathrm{L}$, PLT $412000 /$ LL), inflammatory parameters within normal levels, liver and kidney function tests and indicators of the coagulation system. His immune electrophoresis and biochemical investigations' profiles are summarized in Table 1 and Table 2.

Table 1. Serum protein electrophoresis

\begin{tabular}{|lcc|}
\hline Albumin & $46,9 \%$ & {$[53-68]$} \\
\hline Alpha 1 globulins & $5,7 \%$ & {$[1,0-4,0]$} \\
\hline Alpha 2 globulins & $19,4 \%$ & {$[3,0-14]$} \\
\hline Beta globulins & $17,1 \%$ & {$[8,0-17]$} \\
\hline Gamma globulins & $10,9 \%$ & {$[9,0-22]$} \\
\hline
\end{tabular}


Table 2. Biochemical investigations of the patient

\begin{tabular}{|c|c|c|c|}
\hline Parameters & Reports & Parameters & Reports \\
\hline Albumins & $1.7 \mathrm{~g} / \mathrm{dL}[3.5-5.2]$ & Serum phosfate & $1,24 \mathrm{~mol} / \mathrm{l}[0.78-1.61]$ \\
\hline Total protein & $2.8 \mathrm{~g} / \mathrm{dL}[6.3-8.2]$ & Parathormon & $189 \mathrm{pg} / \mathrm{ml}[6.5-56.9]$ \\
\hline C-reactive protein & $1.4 \mathrm{mg} / \mathrm{l}[0,0-6.0]$ & Vitamin D & 13.3 ng/ml [20-50] \\
\hline Creatinine & $0.52 \mathrm{mg} / \mathrm{dl}[0.65-1.25]$ & HLA B27 & negative \\
\hline AST & $14 \mathrm{IU} / \mathrm{I}[0.0-38$ ] & ESR & $4 \mathrm{~mm}$ after 1 hour $[<8]$ \\
\hline ALT & $28 \mathrm{IU} / \mathrm{I}[0.0-48$ ] & $\mathrm{RF}$ & $<20$ IU/ml [0-30] \\
\hline Bilirubin Total & $0.1 \mathrm{mg} / \mathrm{dl}[0.2-1.20]$ & PSA T & $0.318 \mathrm{ng} / \mathrm{ml}[0-4]$ \\
\hline ALP & 194 IU/I [30-109] & ANA screen & negative \\
\hline GGT & $13 \mathrm{IU} / \mathrm{I}[9.0-37]$ & p-ANCA, c-ANCA & negative \\
\hline APTT & $31.00 \mathrm{sec}[25-41]$ & Uric acid & 3.6 mg/dl [3.2-7.2] \\
\hline INR & $1,02[0.8-1.3]$ & Glucose & 98.8 mg/dl [80-110] \\
\hline Fibrinogen & $2.53 \mathrm{~g} / \mathrm{l}[1.8-3.5]$ & Amylase & 101 U/I [25-125] \\
\hline Serum sodium & $138.5 \mathrm{mmol} / /[135-145]$ & $\begin{array}{l}\text { Daily exrection of calcium in } \\
\text { the urine }\end{array}$ & $\begin{array}{l}3,1 \mathrm{mmol} / 24 \text { hours } \\
{[1.5-7.5]}\end{array}$ \\
\hline Serum potassium & $4.16 \mathrm{mmol} / \mathrm{l}[3.5-5.5]$ & $\begin{array}{l}\text { Daily exrection of phosfate } \\
\text { in the urine }\end{array}$ & $\begin{array}{l}26.35 \mathrm{mmol} / 24 \text { hours } \\
{[13.5-42]}\end{array}$ \\
\hline Serum calcium & $1.7 \mathrm{mmol} / \mathrm{l}[2.11-2.6]$ & Proteinuria & $7.8 \mathrm{mg} / \mathrm{dl}[<15 \mathrm{mg} / \mathrm{dl}]$ \\
\hline
\end{tabular}

The ultrasonography of the abdomen and thyroid, gastroscopy and colonoscopy, aside from small amount of free liquid in abdominal cavity and gastroesophageal reflux, showed no significant abnormalities. The endoscopic image of the duodenum was normal, no villous atrophy was found. The test for Helicobacter pylori was negative.

In computed tomography of the chest a fracture of 7 ribs, with visible healing features, was described (6-8 and 11 on the right side and 9-11 on the left side). The patient denied the chest trauma and was unable to determine when and how the fractures occurred.

In the myelogram, granulocyte derived cell line dominated in the bone marrow, while the activity of the erythroblast and lymphocyte cell line was slightly reduced. There were no blasts or plasma cells in the smear. Further studies ruled out proteinuria and HIV infection, but showed a significant Ig deficiency within all classes, except IgE, a deficiency in all of the lymphocytes subpopulations and moderately elevated fecal 1-antitrypsin levels in the feces.
The conducted stool tests were three times negative for parasites and the calprotectin level was within normal limits.

Moreover, further tests showed: presence of HLA DQ2.2 haplotype (both HLA DQ2.5 and DQ8 haplotypes were absent), negative TG2 antibodies in the IgG class and weakly positive TG2 antibodies in the IgA class $0.83 \mathrm{AU} / \mathrm{mL}$ (TG2 $\lg A<0.8$ negative, TG2 $\lg A>0.8$ positive), which with a significant deficiency of immunoglobulins in this class, brought about a suspicion of CD. After about 3 months, a new gastro-duodenoscopy with biopsy from duodenum confirmed the diagnosis of CD: irregular shape of the villi in duodenum and Marsh IIIA stage lesions in histopathology (Figure 1 and $2 \mathrm{a}, \mathrm{b}$ ). The patient was enrolled in a GFD and about 2 weeks after exclusion of gluten from diet, we observed a significant increase of serum albumin to $2 \mathrm{~g} / \mathrm{dL}$ and total protein to $3.4 \mathrm{~g} / \mathrm{dL}$. The man was afterwards directed in a good condition for further care under control of outpatient gastroenterological clinic. 


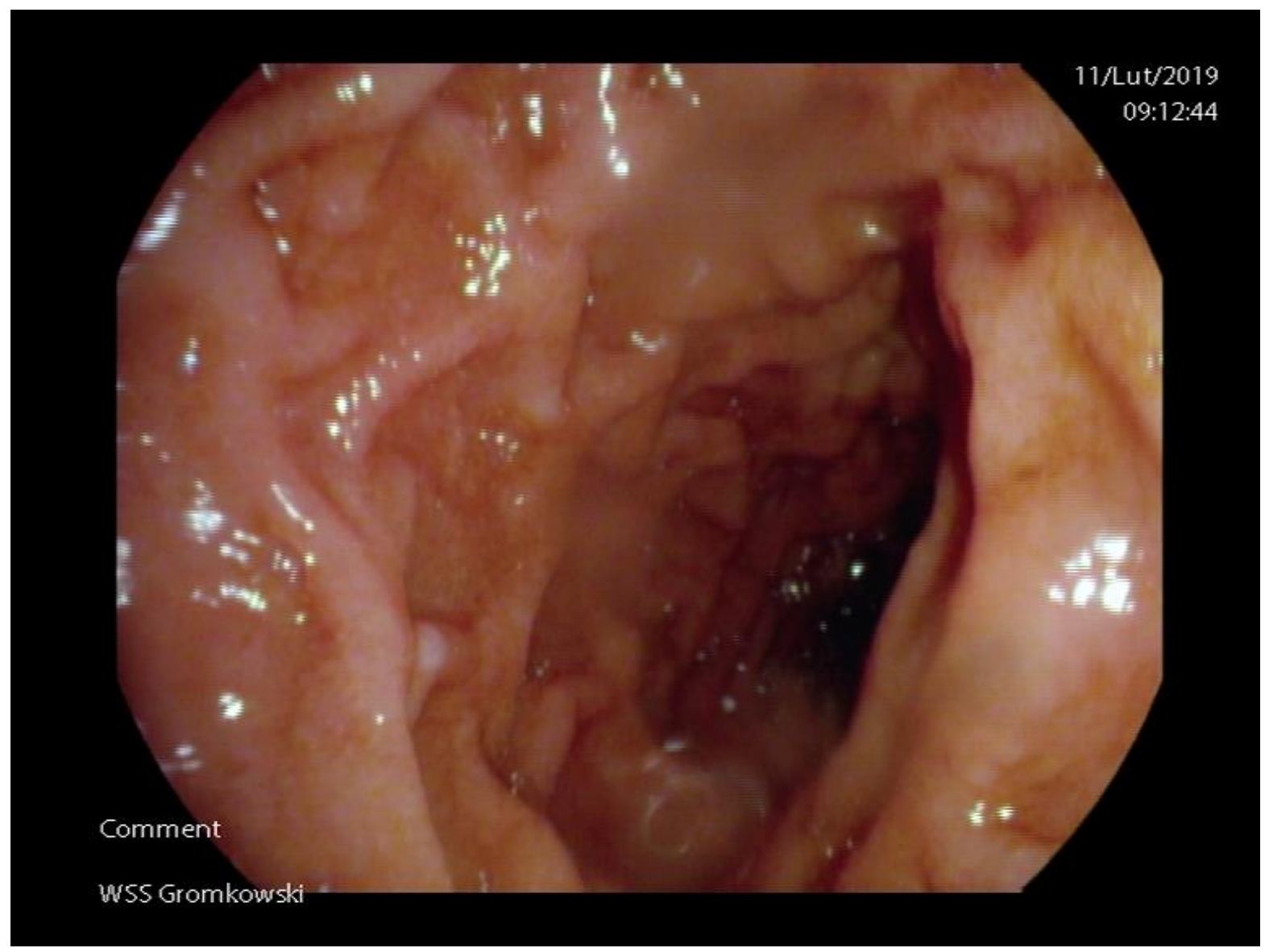

Fig. 1. Image of duodenum in UGI Endoscopy

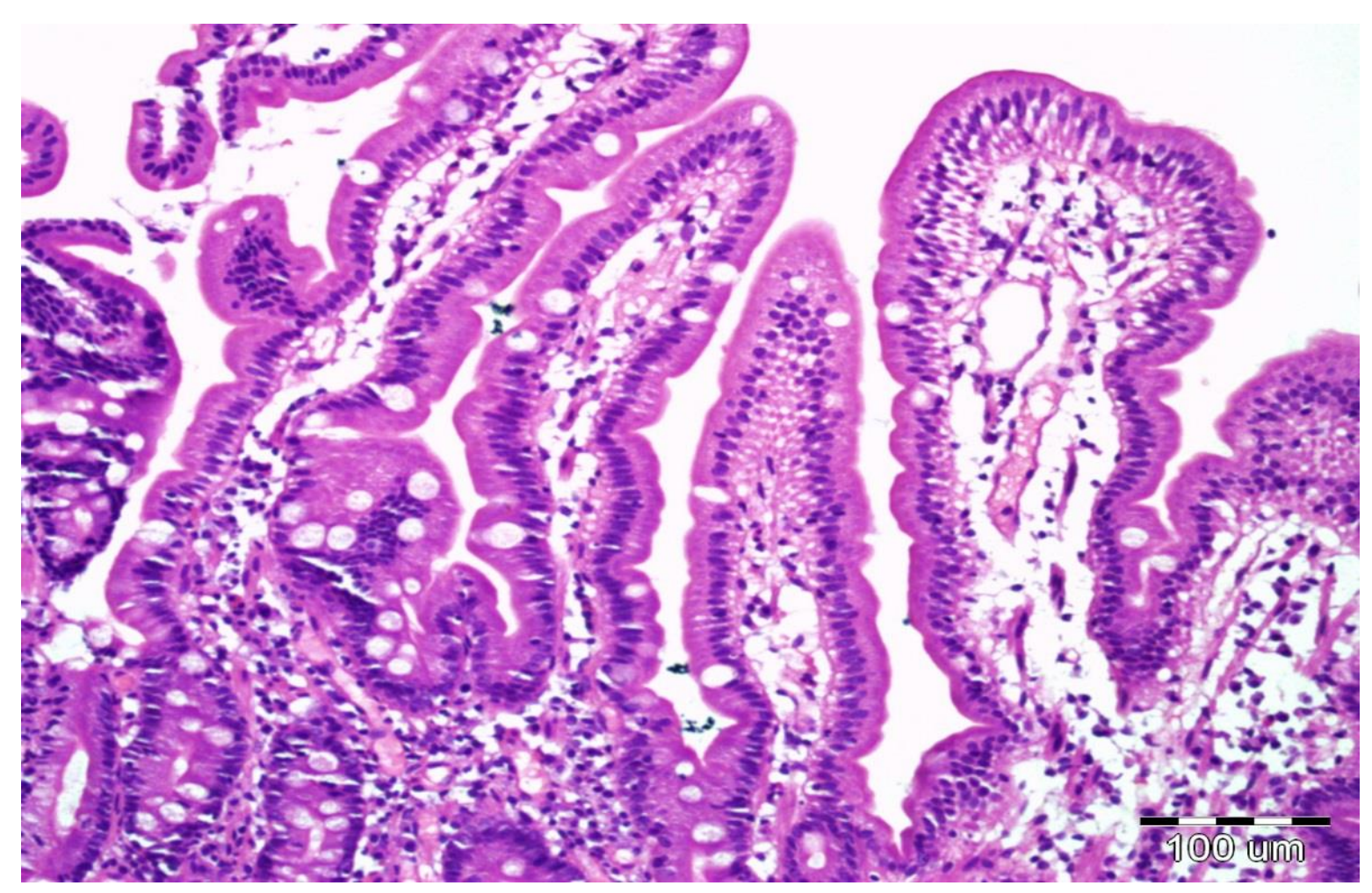

Fig. 2 a. Histopathological examination: Marsh IIIA stage lesions (HE, x10) 

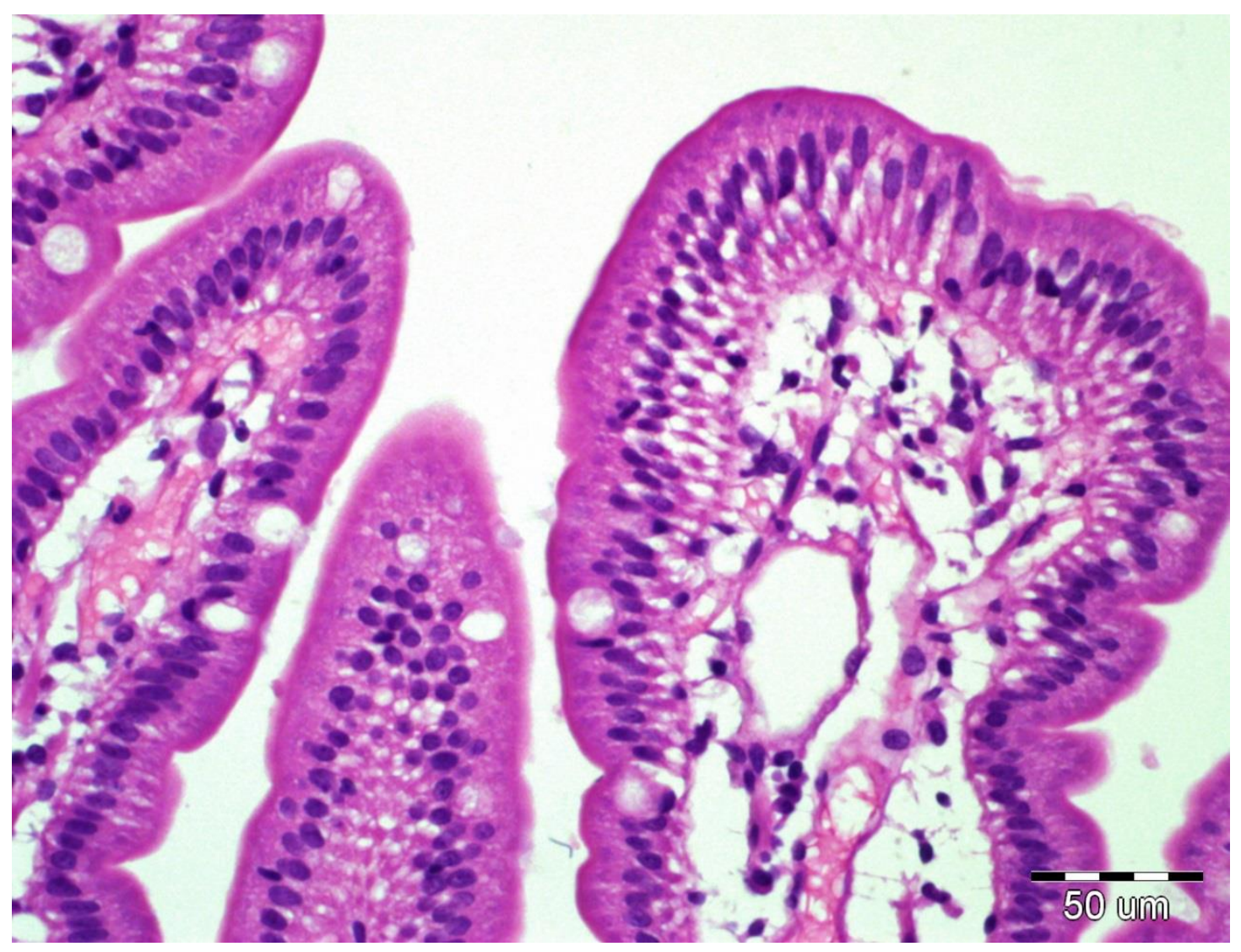

Fig. 2 b. Histopathological examination: Marsh IIIA stage lesions (HE, x20)

\section{Discussions}

Despite the growing awareness and knowledge of the $C D$, its diagnosis still remains challenging. Many patients are undiagnosed for many years, in spite of symptoms, so time from onset of the disease to its definitive diagnosis can take up to even 12 years [9]. Moreover, some patients, in particular with nonspecific symptoms or asymptomatic course, may never be diagnosed. It was reported that the estimated frequency of occult (not diagnosed) CD among subjects between $18-50$ years was $1.1 \%$ of the general population, whereas patients aged 18-29 accounted for a group of the highest prevalence (1.4\%) [11].

The presented case shows a rare course of $C D$ in a 38-year-old man, whose first and practically the only symptom of the disease was a pathological fracture of the ribs. Disorders of calcium absorption in CD may cause hyperparathyroidism, which together with vitamin $\mathrm{D}$ deficiency leads to osteopenia and osteoporosis [12, 13]. The above- mentioned mechanism was the main cause of pathological changes and abnormal laboratory tests (hypocalcemia, elevated values of alkaline phosphatase and parathyroid hormone). In addition, despite the absence of intestinal celiac disease symptoms (including, in particular, clinical manifestations of protein losing enteropathy or malabsorption syndrome), proper nutrition and good general patient's condition, we observed profound deficits of albumin and total protein in the blood serum resulting in secondary immunodeficiency. Explanation of this fact is not obvious, but it might have been caused by a long, mild course of the disease, resulting in slow, asymptomatic, progressive loss of proteins, while poorly expressed symptoms of hypoalbuminemia (periodically occurring left knee edema, small amount of free liquid in abdominal cavity), may be explained by cardiac and venous system efficiency. It is worth mentioning that, after applying GFD, no peritoneal effusions were identified by USG, while the previously present knee edema disappeared. 
Moreover, it should be emphasized that significant protein deficiencies and secondary immunoglobulin shortage were probably the cause of the weakly positive TG2 antibodies in the IgA class and might be the cause of negative TG2 antibody in IgG class, which caused diagnostic difficulties. Only after obtaining presence of HLA DQ2.2 haplotype, the gastroscopy was repeated with the biopsy of duodenum, which made the diagnosis possible. In addition, the histopathological examination of duodenum and positive TG2 antibodies (IgA class), enabled us to rule out non-celiac gluten sensitivity as another potential entity in differential diagnosis.

Hypoalbuminemia and hypocalcemia are often found in CD; however, such a deep protein deficiencies and ribs' fractures as the first manifestation of the disease without symptoms of malabsorption syndrome, is

\section{References}

1. Gujral N, Freeman HJ, Thomson AB. Celiac disease: prevalence, diagnosis, pathogenesis and treatment. World J Gastroenterol 2012; 18(42):6036-6059.

2. Leffler DA, Schuppan D. Update on serologic testing in celiac disease. Am J Gastroenterol 2010; 105(12):2520-2524.

3. Ludvigsson JF, Card TR, Kaukinen $\mathrm{K}$, et al. Screening for celiac disease in the general population and in high-risk groups. United European Gastroenterol J 2015; 3(2):106-120.

4. Sharma M, Singh $P$, Agnihotri $A$, et al. Celiac disease: a disease with varied manifestations in adults and adolescents. J Dig Dis 2013; 14(10):518-525.

5. Pinto-Sanchez MI, Bercik $P$, Verdu EF, et al. Extraintestinal manifestations of celiac disease. Dig Dis 2015; 33(2):147-154.

6. Biagi F, Schiepatti A, Maiorano G, et al. Risk of complications in coeliac patients depends on age at diagnosis and type of clinical presentation. Dig Liver Dis 2018; 50(6):549552.

7. Rubio-Tapia A, Hill ID, Kelly CP, et al. ACG clinical guidelines: diagnosis and management of celiac disease. Am J Gastroenterol 2013; probably the first such case described in the literature.

\section{Conclusion}

Celiac disease should be considered in differential diagnosis in every patient with osteoporotic fractures and profound hypoalbuminemia, despite the absence of intestinal symptoms.

\section{Consent}

Written informed consent was obtained from the patient for publication of this case report and accompanying images.

\section{Competing interests}

The authors declare that they have no competing interests.

All the authors have read and accepted the manuscript.

108(5):656-676; quiz 677.

8. Kowalski $K$, Mulak $A$, Jasinska $M$, et al. Diagnostic challenges in celiac disease. $A d v$ Clin Exp Med 2017; 26(4):729-737.

9. Cichewicz AB, Mearns ES, Taylor A, et al. Diagnosis and treatment patterns in celiac disease. Dig Dis Sci 2019.

10. Newnham ED, Shepherd SJ, Strauss BJ, et al. Adherence to the gluten-free diet can achieve the therapeutic goals in almost all patients with coeliac disease: A 5-year longitudinal study from diagnosis. J Gastroenterol Hepatol 2016; 31(2):342-349.

11. Choung RS, Larson SA, Khaleghi S, et al. Prevalence and morbidity of undiagnosed celiac disease from a community-based study. Gastroenterology 2017; 152(4):830-839.e5.

12. McNicholas BA, Bell $M$. Coeliac disease causing symptomatic hypocalcaemia, osteomalacia and coagulapathy. BMJ Case Rep 2010; 2010.

13. Ganji R, Moghbeli $M$, Sadeghi $R$, et al. Prevalence of osteoporosis and osteopenia in men and premenopausal women with celiac disease: a systematic review. Nutr J 2019; $18(1): 9$. 